\title{
Kondisi gigi yang masih lengkap mempengaruhi kualitas hidup manula di Kota Makassar (Condition of complete dentition affects the quality of life of the elderly in Makassar)
}

\author{
${ }^{1}$ Prastuti Wulandari Kosasih, ${ }^{2}$ Eri H. Jubhari \\ ${ }^{1}$ Mahasiswa tahap profesi \\ ${ }^{2}$ Bagian Prostodonsia \\ Fakultas Kedokteran Gigi Universitas Hasanuddin \\ Makassar, Indonesia
}

\begin{abstract}
Aging is a natural process which causes physical, psychological, and social deteriorations, so it can cause problems to the elderly, especially health problems in Makassar. The local office of Health Department in Makassar determined the optimum degree of health in accordance with result of indicators of Healthy Indonesia 2010 which were indicated by the dental and oral health as an element of the quality of life. This research aims to observe the effect of complete dentition on the quality of life of the elderly in Makassar. With the observational analytic study using a cross-sectional design, the sample were chosen from the elderly who inhabit and settle in Makassar, South Sulawesi, above 60 years old and had $\geq 20$ teeth. The primary data were collected using OHIP-14 questionnaire. The results of simple linear regression test using SPSS version 22 indicate that the elderly with complete dentition have a significance level of 0.003 which is smaller compared with the significance criteria (0.05). It was concluded that the condition of complete dentition affect the quality of life of the elderly in Makassar.
\end{abstract}

Keywords: complete dentition, elderly, quality of life, Makassar

\begin{abstract}
ABSTRAK
Penuaan adalah suatu proses yang terjadi secara alami yang berdampak pada kemunduran fisik, psikologis maupun sosial, sehingga dapat menimbulkan masalah pada diri manula, khususnya masalah kesehatan di Kota Makassar. Dinas Kesehatan Kota Makassar menetapkan derajat kesehatan optimal sesuai indikator Indonesia Sehat 2010 yang dapat dilihat dari unsur kualitas hidup yaitu kesehatan gigi dan mulut. Penelitian ini dimaksudkan untuk mengamati pengaruh kondisi gigi yang masih lengkap terhadap kualitas hidup manula di Kota Makassar. Dengan penelitian observasi analitik dan rancangan cross sectional, ditentukan sampel yaitu manula yang menetap di Kota Makassar, Sulawesi Selatan yang berumur 60 tahun ke atas dan masih memiliki $\geq 20$ gigi. Data primer dikumpulkan dengan kuesioner OHIP-14. Hasil uji regresi linear sederhana menggunakan SPSS versi 22, menunjukkan kondisi gigi yang masih lengkap mempunyai nilai taraf signifikansi 0,003 yang lebih kecil dibandingkan kriteria signifikan $(0,05)$, sehingga disimpulkan kondisi gigi yang masih lengkap mempengaruhi kualitas hidup manula di Kota Makassar.
\end{abstract}

Kata kunci: kondisi gigi lengkap, manula, kualitas hidup, Makassar

Koresponden: Prastuti Wulandari Kosasih,E-mail: prastutiwulandari@yahoo.co.id

\section{PENDAHULUAN}

Menua adalah suatu proses yang terjadi secara terus-menerus secara alami yang berdampak pada kemunduran fisik,psikologis,maupun sosial sehingga dapat menimbulkan masalah pada diri manula itu sendiri maupun orang lain. ${ }^{1}$ Sesuai Undang-Undang Nomor 13 tahun 1998, usia lanjut adalah usia jika seseorangyang telah mencapai usia 60 tahunke atas. ${ }^{2}$ World Health Organization (WHO) memperkirakan kenaikan penduduk berusia lanjut pada tahun 2025 dibandingkan tahun 1990 di China (220\%), India $(242 \%)$, Thailand (337\%), serta Indonesia (440\%). Nampaklah Indonesia akan menjadi negara dengan kenaikan manula tertinggi di dunia. ${ }^{3}$ Peningkatan jumlah manula menuntut perbaikan dan peningkatan kualitas kesehatan, khususnya di Makassar yang jumlah manulanya mencapai 74.743 jiwa pada tahun 2012, karena kesehatan umum memegang peranan penting terhadap kualitas hidup manula. ${ }^{2,45}$
Kualitas hidup menurut WHO yang dikutip oleh Wangsarahardja, adalah persepsi seseorang dalam konteks budaya dan normanya yang sesuai dengan tempat hidup orang tersebut, serta berkaitan dengan tujuan, harapan, standar, dan rasa kepedulian selama hidup. ${ }^{6}$ Salah satu faktor yang mempengaruhi kualitas hidup manula adalah kesehatan gigi dan mulut. ${ }^{6-7}$ Kesehatan gigi dan mulut menurut WHO adalah keadaan bebas dari nyeri kronik pada rongga mulut dan wajah, kanker rongga mulut dan tenggorokan, luka pada rongga mulut, kelainan kongenital, seperti celah bibir dan atau palatum, penyakit periodontal, kerusakan dan kehilangan gigi, dan penyakit atau gangguan lain yang mempengaruhi rongga mulut. ${ }^{8}$ WHO menyatakan, seperti yang dikutip Effendy dkk, pencapaian kesehatan gigi dan mulut dapat dilihat dari kondisi penduduk kelompok usia 65-74 tahun yang hanya $5 \%$ tidak bergigi dan $75 \%$ memiliki gigi yang lengkap dengan jumlah minimal 20 gigi 
yang dapat berfungsi. ${ }^{9}$ Kualitas hidup yang terkait dengan kesehatan gigi dan mulut pada manula diukur menggunakan kuesioner OHIP-14 yang terdiri dari tujuh dimensi (keterbatasan fungsi, rasa sakit fisik, ketidaknyamanan psikis, ketidakmampuan fisik, ketidakmampuanpsikis, danketidakmampuan sosial, serta keterhambatan)yang merupakan dampak akibat dari kelainan atau permasalahan pada rongga mulut yang akan berpengaruh pada kualitas hidup. ${ }^{10}$

Penelitian ini dimaksudkan untuk mengamati pengaruh kondisi gigi yang masih lengkap terhadap kualitas hidup manula di Kota Makassar.

\section{BAHAN DAN METODE}

Penelitian observasi analitik dengan rancangan cross sectional ini dilakukan di Kota Makassar pada Bulan April hingga Juni Tahun 2014. Populasi adalah manula yang tinggal di Kota Makassar, sedangkan sampel adalah manula yang menghuni dan menetap di Kota Makassar, berumur 60 tahun ke atas, dan memiliki gigi minimal 20 gigi. Penarikan sampel menggunakan stratified random sampling, yang lalu yang dibagi menjadi 3 kategori, yaitu area pinggiran (Kecamatan Ujung Tanah), area tengah (Kecamatan Tamalate), dan pusat (Kecamatan Ujung Pandang). Sampel yang sesuai kriteria inklusi diberi penjelasan mengenai penelitian yang akan dilakukan, dimintai persetujuan, dilakukan pemeriksaan intra oral, dan diminta menjawab kuesioner OHIP-14 sesuai dengan keluhan yang dirasakannya. Data ditabulasi dan dianalisis menggunakan uji regresi linear sederhana pada program SPSS dengan taraf signifikansi $5 \%{ }^{1{ }^{11}}$

\section{HASIL}

Berdasarkan penelitian yang dilakukan pada 163 sampel, maka diperoleh hasil yang tampak pada tabel 1. Dari penelitian ini didapatkan hasil bahwa sampel yang berusia lanjut lebih banyak $(91,42 \%)$ dibanding dengan sampel berusia lanjut tua $(8,58 \%)$. Sampel perempuan $(67,49 \%)$ lebih banyak dibanding dengan sampel laki-laki(32,51\%). Sebanyak 29,45\% sampel tidak sekolah. Sampel laki-laki dengan kualitas hidup baik $(96,2 \%)$ lebih banyak dibandingkan dengan perempuan yang kualitas hidupnya baik $(86,4 \%)$.

Untukmengetahui kualitas hidup manula dengan kondisi gigi yang masih lengkap maka kualitas hidup dibagi menjaditiga tingkatan, yaitu baik, sedang, dan buruk. ${ }^{12}$ Pada tabel 2, tampak semua kualitas hidup manula dengan kondisi gigi yang masih lengkap ditinjau dari 7 dimensi OHIP-14 tergolong baik.

Pada tabel 3, terlihat bahwa dimensi 1-4 memiliki taraf signifikansi yang lebih besar dari pada kriteria signifikan, sedangkan dimensi 5-7 memiliki taraf signifikansi yang lebih kecil dari kriteria signifikan.

\section{PEMBAHASAN}

Berdasarkan tabel 1 mayoritas sampel penelitian berusia lanjut (60-74 tahun), hal ini menunjukkan usia harapan hidup (UHH) manula di Makassar berada pada rentang umur 60-74 tahun yang sesuai dengan rerata UHH di Kota Makassar yang mencapai 74,05 tahun pada tahun $2012 .{ }^{13}$ Sampel perempuan lebih banyak daripada sampel laki-laki yaitu $67,5 \%$ berbanding $32,5 \%$. Sampel perempuan lebih banyak karena sebagian besar perempuan berusia lanjut lebih

Tabel 1 Karakteristik dan kategori kualitas hidup sampel berdasarkan distribusi usia, jenis kelamin, dan tingkat pendidikan

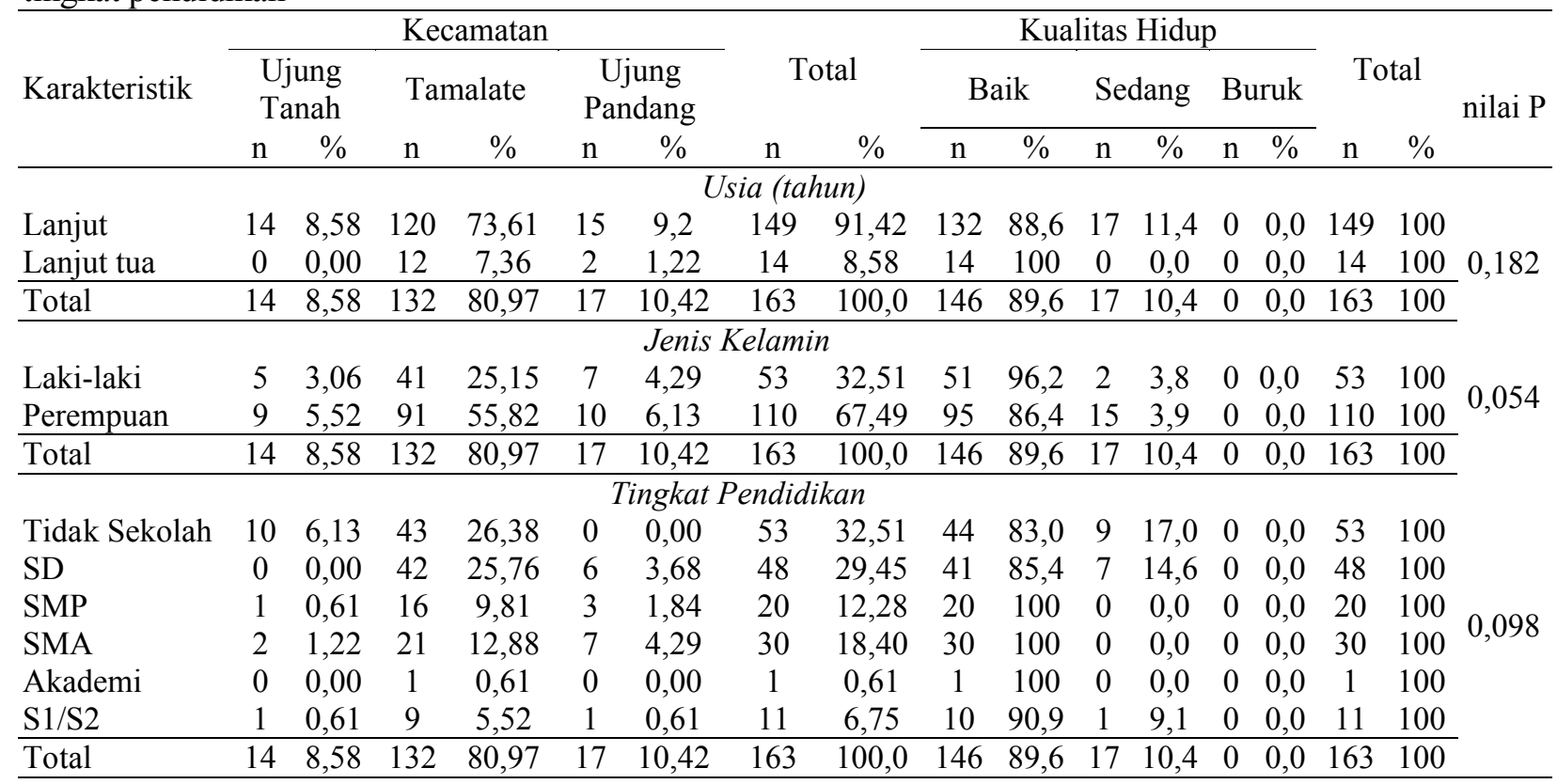

Usia lanjut (60-74), Usia lanjut tua (75-90) 
Tabel 2 Kualitas hidup manula dengan kondisi gigi yang masih lengkap di Kota Makassar

\begin{tabular}{|c|c|c|c|c|c|}
\hline \multirow[b]{2}{*}{ No } & \multirow[b]{2}{*}{ Item Pertanyaan OHIP-14 } & \multirow[b]{2}{*}{$\begin{array}{c}\text { Jumlah } \\
\text { Skor }\end{array}$} & \multicolumn{3}{|c|}{ Kualitas Hidup } \\
\hline & & & $\begin{array}{c}\text { Baik } \\
(<217,33)\end{array}$ & $\begin{array}{c}\text { Sedang } \\
(217,33-434,67)\end{array}$ & $\begin{array}{c}\text { Buruk } \\
(\geq 434,67)\end{array}$ \\
\hline 1 & Kesulitan dalam mengucapkan kata/kalimat & 47 & $\sqrt{ }$ & - & - \\
\hline 2 & Tidak dapat mengecap rasa dengan baik & 118 & $\sqrt{ }$ & - & - \\
\hline 3 & Sakit di rongga mulut & 170 & $\sqrt{ }$ & - & - \\
\hline 4 & Tidak nyaman ketika mengunyah makanan & 102 & $\sqrt{ }$ & - & - \\
\hline 5 & Merasa khawatir/ cemas & 70 & $\sqrt{ }$ & - & - \\
\hline 6 & Merasa tegang & 84 & $\sqrt{ }$ & - & - \\
\hline 7 & Jumlah makanan yang dikonsumsi kurang memuaskan & 86 & $\sqrt{ }$ & - & - \\
\hline 8 & Terhenti saat makan & 93 & $\sqrt{ }$ & - & - \\
\hline 9 & Sulit merasa rileks & 45 & $\sqrt{ }$ & - & - \\
\hline 10 & Merasa malu & 71 & $\sqrt{ }$ & - & - \\
\hline 11 & Mudah tersinggung & 57 & $\sqrt{ }$ & - & - \\
\hline 12 & Kesulitan melakukan kegiatan sehari-hari & 84 & $\sqrt{ }$ & - & - \\
\hline 13 & Hidup terasa kurang memuaskan & 61 & $\sqrt{ }$ & - & - \\
\hline 14 & Susah untuk melakukan apapun & 76 & $\sqrt{ }$ & - & - \\
\hline & Jumlah & 1162 & & & \\
\hline & Rerata & 82 & & & \\
\hline
\end{tabular}

Tabel 3 Nilai taraf signifikansi pada setiap dimensi OHIP-14

\begin{tabular}{ccc}
\hline No & Dimensi OHIP-14 & Taraf Signifikansi \\
\hline 1 & Keterbatasan fungsi & 0,072 \\
2 & Rasa sakit fisik & 0,152 \\
3 & Ketidaknyamanan psikis & 0,055 \\
4 & Ketidakmampuan fisik & 0,102 \\
5 & Ketidakmampuan psikis & 0,026 \\
6 & Ketidakmampuan sosial & 0,014 \\
7 & Keterhambatan & 0,009 \\
\hline \multicolumn{2}{c}{ Kondisi gigi yang lengkap } & 0,003 \\
\hline
\end{tabular}

memilih menetap di rumah daripada bekerja di luar, sedangkan sampel laki-laki sebagian besar masih memilihuntuk bekerja di luar sehingga sampel yang ditemui di lokasi penelitian sebagian besar berjenis kelamin perempuan.

Sebanyak $32,5 \%$ sampel tidak sekolah serta hanya $11(6,7 \%)$ sampel yang mencapai pendidikan S1/S2. Hal ini disebabkan waktu mereka masih usia sekolah, sekolah masih jarang dan hanya orang-orang tertentu yang dapat bersekolah. Persentase manula laki-laki dengan kualitas hidup baik lebih besar dari pada persentase manula perempuan dengan kualitas hidup baik, yakni $96,2 \%$ berbanding $86,4 \%$. Hal ini menunjukkan bahwa laki-laki berusia lanjutmemiliki kualitas hidup yang lebih baik dibandingkan dengan perempuan berusia lanjut. Hal ini sejalan dengan penelitian dari Sadockyang dikutip Amurwaningsih $\mathrm{dkk}^{14}$ yang menunjukkan bahwa kualitas hidup lakilaki jauh lebih baik dibandingkan perempuan karena adanya prevalensi depresi dan kecemasan yang lebih besar pada perempuan dari pada laki-laki; terdapat perbedaan sekresi hormon, tekanan psikososial, dan tipe perilaku antara laki-laki dengan perempuan. ${ }^{14}$
Pada tabel 2 terlihat bahwa rata-rata manula memiliki skor yang rendah pada setiap dimensi OHIP14, yaitu di bawah 217,33, sehingga kualitas hidup manula dengan kondisi gigi yang masih lengkap di Makassar dikategorikan baik. Hal ini memberikan gambaran tentang keberhasilan program kesehatan dan program pembangunan sosial ekonomi yang berdampak pada kualitas hidup masyarakat di Kota Makassar. ${ }^{13}$

Pada tabel 3, beberapa dimensi OHIP-14 yakni 1-4 yang menyangkut masalah keterbatasan fungsi, rasa sakit fisik, ketidaknyamanan psikis, maupun ketidakmampuan fisik memperlihatkan nilai taraf signifikansi yang lebih besar dibandingkan dengan nilai kriteria signifikan $(0,05)$. Hal ini menunjukkan bahwakondisi gigi yang masih lengkap pada manula tidak berpengaruh pada 4 dimensi pertama OHIP14 tersebut. Tidak adanya pengaruh antara kondisi gigi yang masih lengkap pada dimensi keterbatasan fungsi (kesulitan mengucapkan kata atau kalimat serta berkurangnya kemampuan mengecap rasa dengan baik) terjadi karena adanya penurunan fungsi indra pengecap dan otot-otot dalam rongga mulut, sehingga manula sulit mengucap kata dan mengecap rasa dengan baik. Rasa nyeri pada rongga mulut umumnya disebabkan oleh adanya perubahan dan kemunduran fungsi dari kelenjar saliva yang terjadi seiring dengan meningkatnya usia, mengakibatkan pengurangan jumlah aliran saliva sehingga terjadi rasa ketidaknyamanan pada rongga mulut, nyeri, peningkatan karies gigi dan infeksi mulut, serta kesulitan bicara dan menelan makanan. ${ }^{15}$ Kondisi gigi yang masih lengkap tidak mempengaruhi kecemasan manula. Menurut Mehrstedt dan Schierz yang dikutip oleh Amurwaningsih dkk; dijelaskan 
bahwa kecemasan tidak langsung mempengaruhi kualitas hidup seseorang karena terdapat aspek yang lebih berhubungan dengan kualitas hidup, yaitu kondisi kejiwaan, kesehatan umum, dan fungsi sosial dari seseorang. ${ }^{14}$ Ketidakmampuan fisik (perasaan tidak puas pada saat mengkonsumsi makanan dan terpaksa berhenti saat makan) juga bukan dampak kondisi gigi yang masih lengkap. Ketidakmampuan fisik disebabkan penurunan kapasitas fisik. Hal ini ditandai dengan penurunan massa dan kekuatan otot akibat proses degeneratif dan tidak adanya upaya meminimalkan proses penuaan melalui aktivitas fisik dan kontrol kesehatan secara rutin. Akibatnya, manula dengan kualitas fisik yang kurang baik akan mengalami berbagai hambatan dalam melaksanakan aktivitasnya. ${ }^{16}$

Pada keadaan manula dengan kondisi gigi yang masih lengkap diketahui dapat mempengaruhi dimensi 5-7 dari OHIP-14, yaitu ketidakmampuan kejiwaan (perasaan susah merasa rileks dan malu), ketidakmampuan sosial (mudah tersinggung dan sulit melakukan kegiatan sehari-hari), dan keterhambatan (merasakan hidupnya tidak memuaskan dan susah melakukan apapun). ${ }^{17}$ Menurut Nugrohoyang dikutip oleh Rantepadang, ${ }^{7}$ dijelaskan bahwa pada proses menua, sensitivitas emosi seseorang meningkat, yang akhirnya menjadi sumber banyak masalah, seperti semakin perasanya orang yang memasuki usia lanjut; sedangkan kesibukan dan interaksi sosial menurun sehingga berdampak pada kebahagiaan, kesepian, dan kebosanan seseorang yang disebabkan oleh rasa tidak diperlukan.
Untuk menarik simpulan secara umum, melalui uji regresi linear sederhana, maka didapatkan nilai taraf signifikansi yang sangat kecil, yakni 0,003 dibandingkan dengan nilai kriteria signifikan 0,05 sehingga dikatkan bahwa ada pengaruh kondisi gigi yang masih lengkap terhadap kualitas hidup manula di Kota Makassar. Hal ini karena gigi-geligi sangat diperlukan dalam proses mastikasi, mempengaruhi estetik, kepercayaan diri, dan psikososial manula sehingga berdampak pada kualitas hidup manula tersebut. ${ }^{14,18}$ Hal ini juga sejalan dengan penelitian yang dilakukan oleh Biazevic yang dikutip oleh Khai, ${ }^{19}$ yang menjelaskan bahwa akibat edentulus, karies, penyakit periodontal, ditambah akibat komorbiditas seperti diabetes dan serostomia memberi akibat yang berdampakpada kondisi fisik, ekonomis, dan psikologis termasuk kemampuan mengunyah, makan, dan bicara. Akibat dari penyakit oral ini memberikan dampak terhadap kualitas hidup manula berupa menurunnya interaksi sosial, rasa sejahtera, harga diri, dan perasaan tidak berguna. ${ }^{19}$

Disimpulkan bahwa kondisi gigi yang masih lengkap mempengaruhi kualitas hidup manula di Kota Makassar. Untuk itu disarankan perlu upaya menyadarkan masyarakat sejak dini agar lebih peduli terhadap kesehatan gigi dan mulut sehingga kondisi gigi yang lengkap ( $\geq 20$ gigi) dapat dipertahankan hingga berusia lanjut, sehingga kualitas hidupnya tetapbaik. Untuk mencapainya, dibutuhkan perhatian dari Dinas Kesehatan Kota Makassar dan pihak terkait agar berupaya meningkatkan pelayanan kesehatan gigi dan mulut khususnya manula di Kota Makassar.

\section{DAFTAR PUSTAKA}

1. Ratmini NK, Arifin. Hubungan kesehatan mulut dengan kualitas hidup lansia. J Ilmu Gizi 2011;2: 139-45

2. Undang-Undang Nomor 13 Tahun 1998 tentang kesejahteraan lanjut usia. [internet]. Available from: URL:http:// www.dpr.go.id/uu/uu1998/UU13.pdf. Diakses pada 12 Desember 2013

3. Handayani D, Wahyuni. Hubungan dukungan keluarga dengan kepatuhan lansia dalam mengikuti posyandu lansia di posyandu lansia jetis Desa Krajan Kecamatan Weru Kabupaten Sukoharjo. J Kesehatan Gaster 2011;2(1): 49-50

4. Kementerian Kesehatan RI. Gambaran kesehatan lanjut usia di Indonesia. Jakarta: Buletin Jendela Data dan Informasi Kesehatan; 2013. h.1-4

5. Nisa H. Faktor determinan status gizi lansia penghuni panti werdha pemerintah DKI Jakarta tahun 2004. Media Litbang Kesehatan 2006; 16(3): 24-5

6. Wangsarahardja K, Olly D, Eddy K. Hubungan antara status kesehatan mulut dan kualitas hidup pada lanjut usia. Universa Medicina 2007; 6(4): 187-9

7. Rantepadang A. Interaksi sosial dan kualitas hidup lansia di Kelurahan Lansot Kecamatan Tomohon Selatan. J Kedokteran Umum 2012;1(1): 62

8. World Health Organization. Oral health. [internet]. Available from: URL:http://www.who.intopics/oral health/en/. Diakses pada 9 Desember 2013

9. Effendy A, Anton R, Peter A. Hubungan willingness to pay (WTP) dengan demand terhadap pelayanan gigi tiruan peserta posbindu di Serpong, Tangerang. Cakradonya Dent 2011;10: 179

10. Jain M, Kaira LS, Sikka G. How do age and tooth loss affect oral health impacts and quality of life? a study comparing two state samples of Gujarat and Rajasthan. J Dent Tehran University of Medical Sciences 2012:9(2): 135-8

11. Usman H, Purnomo SA. Pengantar statistika. Jakarta: PT Bumi Aksara; 2011. h.129, 183

12. Fajar I, Isnaeni DTN, Astutik P, Isman A. Statistika untuk praktisi kesehatan. Yogyakarta: Graha Ilmu; 2009. h.58 
13. Dinas Kesehatan Kota Makassar. Profil kesehatan Makassar tahun 2007, 2009, 2011, 2012 [internet]. Available from: URL:http://datinkessulsel.wordpress.com/profil-kesehatan/makassar. Diakses pada 8 Desember 2013

14. Amurwaningsih M, Nisaa U, Darjono A. Analisis hubungan kualitas hidup yang berhubungan dengan kesehatan mulut (OHRQoL) dan status kecemasan dengan status nutrisi pada masyarakat usia lanjut. Fakultas Kedokteran Gigi Unissula 2010: 4-5

15. Manurung AK. Pengaruh xerostomia terhadap kesehatan gigi dan mulut terkait kualitas hidup pada usila. Laporan akhir hasil penelitian karya tulis ilmiah. Semarang: Universitas Diponegoro; 2012.p.87-8

16. Junaidi S. Pembinaan fisik lansia melalui aktivitas olahraga jalan kaki. J Media Ilmu Keolahragaan Indonesia 2011: 1(1):18-9

17. Mehmood A, Bilal A, Nazia Y. Oral health related quality of life in complete dentures. Pakistan Oral Dent $2009: 29$ (2): $397-400$

18. Kusdhany L, Sundjaja Y, Fardaniah S, Ismail R. Oral health related quality of life in Indonesian middle-aged and elderly women. Med J Indonesia 2011:20(2): 63-4

19. Khai R. Pravalensi diabetes melitus dan hubungannya dengan kualitas hidup lanjut usia di masyarakat. Universa Medicina 2007;26(1): 19-20 